\title{
Use of EIS, Polarization and Electrochemical Noise Measurements to Monitor the Copper Corrosion in chloride media at different temperatures
}

\author{
Weiwei Cheng ${ }^{1}$, Shengyun $\mathrm{Luo}^{2}$, Yu Chen ${ }^{2,3, *}$ \\ ${ }^{1}$ School of Information Science and Technology, Zhejiang Sci-Tech University, Hangzhou, Zhejiang \\ 310018, China \\ ${ }^{2}$ School of Materials Science and Engineering, Guizhou Minzu University, Guizhou, Guiyang 550025, \\ China \\ ${ }^{3}$ Department of Chemical Engineering and Safety, Binzhou University, Binzhou, Shandong 256600, \\ China \\ "E-mail: chen123yu123@163.com
}

doi:10.20964/2019.05.46

Received: 8 January 2019/ Accepted: 28 February 2019 / Published: 10 April 2019

\begin{abstract}
Different electrochemical methods were applied to monitor the copper corrosion behavior in 0.06 $\mathrm{mol} / \mathrm{L} \mathrm{NaCl}$ solution. Some important electrochemical parameters, including the polarization resistance $R_{\mathrm{p}}$ and charge transfer resistance $R_{\mathrm{ct}}$ were derived from linear polarization and electrochemical impedance spectroscopy, respectively. The results indicated that the calculated noise resistance $R_{\mathrm{n}}$, which was obtained from moving average removal (MAR) or polynomial trend removal (PTR) trend removal method, could not equate with $R_{\mathrm{p}}$ or $R_{\mathrm{ct}}$ in the present study. However, the active pitting energy $E_{\mathrm{c}}$, deduced from FWT method without trend removal technique, shows the similar variation trend with $R_{\mathrm{p}}$ or $R_{\mathrm{ct}}$. Hence, electrochemical noise can be utilized as a nondestructive technique to on-line monitor the corrosion progress which can be performed with simple equipment. Furthermore, the deduced parameter $E_{\mathrm{c}}$ presents closer relation to the metal surface structure and shows the same variation trend with the corrosion rate and severity.
\end{abstract}

Keywords:copper; electrochemical noise; trend removal

\section{$\underline{\text { FULL TEXT }}$}

(C) 2019 The Authors. Published by ESG (www.electrochemsci.org). This article is an open access article distributed under the terms and conditions of the Creative Commons Attribution license (http://creativecommons.org/licenses/by/4.0/). 